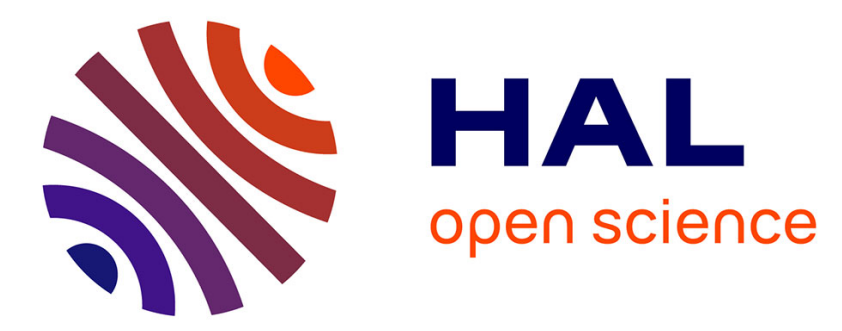

\title{
$6 \mathrm{cmH} 2 \mathrm{O}$ continuous positive airway pressure versus conventional oxygen therapy in severe viral bronchiolitis:
} A randomized trial

Christophe Milési, Stefan Matecki, Samir Jaber, Thibaut Mura, Aurélien Jacquot, Odile Pidoux, Nathalie Chautemps, Aline Rideau Batista Novais, Clémentine Combes, Jean-Charles Picaud, et al.

\section{To cite this version:}

Christophe Milési, Stefan Matecki, Samir Jaber, Thibaut Mura, Aurélien Jacquot, et al.. $6 \mathrm{cmH} 2$ O continuous positive airway pressure versus conventional oxygen therapy in severe viral bronchiolitis: A randomized trial. Pediatric Pulmonology, 2013, 48 (1), pp.45-51. 10.1002/ppul.22533 . hal-02544968

\section{HAL Id: hal-02544968 \\ https://hal.umontpellier.fr/hal-02544968}

Submitted on 17 Apr 2020

HAL is a multi-disciplinary open access archive for the deposit and dissemination of scientific research documents, whether they are published or not. The documents may come from teaching and research institutions in France or abroad, or from public or private research centers.
L'archive ouverte pluridisciplinaire HAL, est destinée au dépôt et à la diffusion de documents scientifiques de niveau recherche, publiés ou non, émanant des établissements d'enseignement et de recherche français ou étrangers, des laboratoires publics ou privés. 


\title{
$6 \mathrm{cmH}_{2} \mathrm{O}$ Continuous Positive Airway Pressure Versus Conventional Oxygen Therapy in Severe Viral Bronchiolitis: A Randomized Trial
}

\author{
Christophe Milési, MD, ${ }^{1}$ Stefan Matecki, MD, PhD, ${ }^{2,3}$ Samir Jaber, MD, PhD, ${ }^{3,4}$ \\ Thibaut Mura, MD, ${ }^{5}$ Aurélien Jacquot, MD, ${ }^{1}$ Odile Pidoux, MD, ${ }^{1}$ Nathalie Chautemps, MD, ${ }^{1}$ \\ Aline Rideau Batista Novais, MD, ${ }^{1}$ Clémentine Combes, Ms, ${ }^{1}$ Jean-Charles Picaud, MD, PhD, ${ }^{1}$ \\ and Gilles Cambonie, $\mathrm{MD}, \mathrm{PhD}^{1 *}$
}

\begin{abstract}
Summary. Objective: To compare the effects of nasal continuous positive airway pressure (nCPAP) and conventional oxygen therapy on the clinical signs of respiratory distress and the respiratory muscle workload in acute viral bronchiolitis. Design: Prospective, randomized, monocentric study carried out in the pediatric intensive care unit (PICU) of a university hospital. Patients: Infants $<6$ months old, admitted to the PICU with severe respiratory syncytial virus bronchiolitis. Intervention: The patients were randomized into two groups for $6 \mathrm{hr}$. The nCPAP group $(\mathrm{n}=10)$ received $6 \mathrm{cmH}_{2} \mathrm{O}$ pressure support delivered by a jet flow generator and the control group $(n=9)$ received an air/oxygen mixture from a heated humidifier. Respiratory distress was assessed by the modified Wood's clinical asthma score (m-WCAS), and inspiratory muscle work was evaluated by calculating the pressure-time product per breath (PTP insp/breath) and per minute $\left(\mathrm{PTP}_{\text {insp }} / \mathrm{min}\right)$ from the esophageal pressure (Pes) recordings. Measurements and Main Results: Compared with control condition, nCPAP decreased m-WCAS [-2.4 (1.05) vs. -0.5 (1.3), $P=0.03]$, PTPes $_{\text {insp }} /$ breath $[-9.7$ (5.7) vs. -1.4 (8.2), $P=0.04]$, PTPes $i n s p / m i n ~[-666$ (402) vs. -116 (352), $P=0.015]$, and $\mathrm{FiO}_{2}[-7$ (10) vs. +5 (15), $P=0.05]$. Significant worsening of $m$-WCAS was only observed in the control group (4/9 vs. $0 / 10, P=0.03$ ). Conclusions: nCPAP rapidly decreased inspiratory work in young infants with acute bronchiolitis. Improvement in the respiratory distress score at $6 \mathrm{hr}$ was proportional to the initial clinical severity, suggesting the importance of rapid nCPAP initiation in the more severe forms of the disease.
\end{abstract}

Key words: acute viral bronchiolitis; continuous positive airway pressure; infant; randomized control trial; respiratory syncytial virus infections.

Funding source: Clinical Research Department of Montpellier University Hospital Centre, Number: AOI 2005.

\section{INTRODUCTION}

In infants under 1-year-old, severe respiratory syncytial virus (RSV) bronchiolitis is the major cause of acute respiratory distress. ${ }^{1}$ However, few prospective randomized studies have been performed, making it difficult to formulate clear-cut recommendations for the management of these patients. ${ }^{2-4}$

Several clinical studies have suggested that continuous positive airway pressure (CPAP) is beneficial in cases of acute viral bronchiolitis. ${ }^{5-11}$ In this disease, the critical narrowing in the peripheral airways results in severe obstruction, with markedly increased respiratory system resistance. ${ }^{12}$ During the expiratory phase of respiration, dynamic collapse of the airways produces a disproportionate decrease in airflow, leading to dynamic hyperinflation and intrinsic end-expiratory pressure (PEEPi). ${ }^{13}$ PEEPi not only decreases compliance, but it
${ }^{1}$ Pediatric Intensive Care Unit, CHU Montpellier, France.

${ }^{2}$ Physiological Department, CHU Montpellier, France.

${ }^{3}$ INSERM ERI 25, Muscle and Pathologies, University Montpellier I, Montpellier, France.

${ }^{4}$ Intensive Care Unit and Transplantation Department, CHU Montpellier, France.

${ }^{5}$ Department of Medical Information, CHU Montpellier, Montpellier, France.

Conflict of interest: None.

*Correspondence to: Gilles Cambonie, MD, PhD, Unité de Réanimation Pédiatrique, CHU de Montpellier, Hôpital Arnaud de Villeneuve, 371 Avenue du Doyen G. Giraud, 34295 Montpellier Cedex 5, France.

E-mail: g-cambonie@chu-montpellier.fr 
also adversely affects the work required to initiate inspiration to overcome the difference between alveolar and upstream pressures at end-expiration. ${ }^{14}$ Hyperinflation generates an extra elastic load from the chest wall and forces respiratory muscles to operate in unfavorable biomechanical conditions, thereby altering the efficiency of force generation by the respiratory muscles. ${ }^{15} \mathrm{~A}$ sixfold increase in the total work of breathing or the inspiratory effort is commonly reported in severe bronchiolitis. $^{13,16,17}$ In response to this higher inspiratory load, the respiratory pattern is modified, with increased breathing frequency and Ti/Ttot ratio. The main consequence of this ventilatory adaptation is a decrease in expiratory time and resulting air trapping. ${ }^{13,17}$

Two recent works observed consistent increases in expiratory time ( $\mathrm{Te}$ ) and a $50 \%$ reduction in inspiratory work immediately following CPAP initiation. ${ }^{13,17}$ The demonstration of increased PEEPi during spontaneous ventilation and the change in breathing pattern with this pressure support suggested that nCPAP improves the work of breathing mainly by offsetting the patient's inspiratory effort to overcome PEEPi. This leads to a decrease in the dynamic collapse of the very compliant upper and lower airways, which is particularly amplified under forceful respirations in this age group. ${ }^{18}$ Ultimately, this airway recruitment helps to empty the lung during expiration, thereby decreasing hyperinflation and the work of breathing.

The methodologies used in these studies of CPAP to treat severe bronchiolitis have been descriptive or retrospective, which has limited the impact of the findings. ${ }^{19}$ Recently, Thia et al. conducted a randomized, cross-over study in 29 infants with moderately severe bronchiolitis that demonstrated the effectiveness of CPAP in reducing capillary $\mathrm{PCO}_{2}$ compared with oxygen therapy. However, very young infants were not included in this trial and the physiological data were limited to blood gases and respiratory and heart rates, potentially explaining the absence of clinical improvement. ${ }^{10}$

On the basis of a pilot study, we designed a prospective and randomized study and hypothesized that CPAP would have a beneficial clinical effect on infants with severe RSV bronchiolitis. Our objective was to assess and compare the effects of nasal CPAP and conventional oxygen therapy on the clinical signs of respiratory distress and the respiratory muscle workload in infants $<6$ months old presenting severe acute RSV bronchiolitis.

\section{MATERIAL AND METHODS}

\section{Patients}

Infants $<6$ months old and hospitalized in our pediatric intensive care unit (PICU) with the clinical diagnosis of bronchiolitis were eligible for this study. The inclusion criteria were the following: (1) RSV bronchiolitis confirmed by nasopharyngeal enzyme immunoassay; (2) severe respiratory distress defined by a modified Wood's clinical asthma score (m-WCAS) $>4$; (3) no invasive or noninvasive ventilation, including nasal continuous positive airway pressure (nCPAP), prior to PICU admission; (4) no underlying cardiopulmonary or neuromuscular disease and no pneumothorax on chest radiograph; and (5) signed authorization by the parents.

\section{Study Protocol}

This prospective, randomized, controlled study was performed during three consecutive RSV epidemic periods, from November 2006 to March 2009. Cardiorespiratory monitoring was started in eligible infants and included pulse oximetry $\left(\mathrm{SpO}_{2}\right)$ and oscillometric measurement of arterial blood pressure (IntelliVue MP70, Philips Medical Systems, Eindhoven, the Netherlands). Transcutaneous (Tc) $\mathrm{PCO}_{2}$ was continuously recorded using a TCM4 (Radiometer, Copenhagen, Denmark).

Initial management consisted of aspiration of secretions, if necessary, and delivery of a humidified air/ oxygen blend from a heating base in order to reach an $\mathrm{SpO}_{2}$ of $94-98 \%$. A $120 \mathrm{ml} / \mathrm{kg}$ venous perfusion with a binary parenteral nutrition preparation was started. Corticosteroid and bronchodilator administration were stopped on admission, and no enteral nutrition was given during the protocol. Chest $X$ rays and capillary blood gas measurements were taken, and the infant was then maintained in a quiet environment for at least $1 \mathrm{hr}$.

Once the diagnosis of RSV-positive bronchiolitis was confirmed by enzyme immunoassay, respiratory distress was quantified using the m-WCAS. ${ }^{17,20-22}$ Then, the inspiratory work was assessed by measuring esophageal pressure (Pes). After these baseline evaluations, the patients were randomized into one of two groups, nCPAP or control, using sequentially numbered, opaque sealed envelopes from the Department of Medical Information of the institution.

nCPAP was generated with the Infant Flow Ventilator (Electro Medical Equipment, Brighton, UK). The flow was adjusted to deliver positive continuous pressure of $6 \mathrm{cmH}_{2} \mathrm{O}$ via a mask connected to a twin injector nozzle fixed to the patient by a specially designed bonnet. The esophageal catheter was left in place.

Infants in the control group continued to receive a heated and humidified air/oxygen mixture delivered through a nasal cannula, which allowed a maximum gas flow of $2.5 \mathrm{~L} / \mathrm{min}$ (MR 850 and RT094, Fisher and Paykel, Villebon, France). In both groups, the air/oxygen blend was adjusted in order to reach an $\mathrm{SpO}_{2}$ of 94 $98 \%$. 
The protocol lasted $6 \mathrm{hr}$ after the allocated treatment was begun. In both groups, m-WCAS was assessed hourly and Pes was measured 1 and $6 \mathrm{hr}$ after the start of the procedure. At any moment during this study, an increase of more than $30 \%$ in m-WCAS justified a switch to the other treatment group.

\section{Clinical Score and Esophageal Pressure Measurement}

A detailed description of the data acquisition and analysis has been reported elsewhere. ${ }^{17,22}$ A single observer, who was not involved in patient care or pressure recordings, quantified the respiratory distress using m-WCAS, with the help of a visual analog scale to standardize the scoring of accessory muscle use and wheezing. An investigator who was unaware of this scoring was designated to measure Pes using an esophageal balloon catheter (Marquat, Boissy-Saint-Léger, France) connected to a differential pressure transducer system. The catheter (with an external diameter of $1.9 \mathrm{~mm}$ ) was inserted orally and placed in the middle portion of the esophagus to estimate intrapleural pressure from the esophageal pressure (Pes). The catheter position was adjusted by continuous online Pes monitoring until a clear oscillating signal with negative deflection was obtained during inspiration. The inspiratory work was estimated from the pressure-time product (PTP) per breath and per minute, defined as the area under the pressure-time curve. ${ }^{23}$ The inspiratory muscle pressure-time product per breath (PTPes insp $_{\text {p }} /$ breath) was calculated by measuring the mean area under the Pes signal between the onset of the inspiratory effort and the end of inspiration ( $\int$ Pes dt) of 30 consecutive and regular respiratory cycles. PTPes insp $_{\text {per minute was }}$ obtained by multiplying the pressure-time products per breath by the breathing frequency $\left(\mathrm{PTPes}_{\text {insp }} / \mathrm{min}=\int\right.$ Pes $\mathrm{dt} \times$ breathing frequency).

\section{Data Analysis}

Based on a pilot study, ${ }^{17}$ we assumed that 15 patients would have to be included to demonstrate a twofold greater decrease in m-WCAS in the nCPAP group, with an alpha risk of $5 \%$ and a power of $80 \%$. In order to overcome the uncertainty of the calculation related to the small sample in the preliminary study, we planned to include 20 patients.

The intention-to-treat analysis was conducted using the last-observation-carried-forward (LOCF) method. Variations in the outcome measures between baseline (H0) and $6 \mathrm{hr}$ (H6) for each group and between groups were assessed using Student's $t$-test or a nonparametric test (Mann-Whitney, Wilcoxon, or Kruskal-Wallis). In a second step, the changes in the outcome measures were compared between the two groups using a linear mixed model for longitudinal data. The model included intercept and random slope effects. Fixed back in the model were time, the arm of randomization, and the interaction between time and the randomized arm. A multivariate analysis of the primary endpoint was achieved by adjusting the results of clinical characteristics when the initial value differed by more than $15 \%$ between the two groups.

Qualitative variables were compared with the chisquare test, or Fischer's exact test when appropriate. The Spearman correlation coefficient was calculated to assess the correlation between continuous variables.

Data are expressed as mean (SE) or absolute frequencies $(\%)$. The significance level was set at 0.05 . Statistical analysis was conducted with the SAS software package, version 9 (SAS Institute, Cary, NC).

\section{Ethical Considerations}

Informed written consent was obtained from the parents of all infants. The study protocol was approved by the Human Protection Committee of Montpellier, France. This clinical trial was recorded on the National Library of Medicine registry (number NCT00513890).

\section{RESULTS \\ Population}

From November 2006 to April 2009, 58 infants presenting RSV bronchiolitis were admitted to the PICU. Thirty-seven of them were not eligible: 25 presented an m-WCAS $<4$, six were older than 6 months, six had been intubated by the ambulance crew before admission, and three had already been treated by nCPAP.

Of the 21 eligible infants, two were not included because the parents declined to sign a consent form. The 19 included infants were 7.5 (1) weeks old, weighed $4.3(0.2) \mathrm{kg}$, and had a clinical risk index for babies (CRIB) score of 2.2 (0.2).

\section{Baseline Characteristics}

At enrollment, the mean baselines values were as follows: m-WCAS: 4.8 (0.2), respiratory rate: 50 (2) breaths/min, $\mathrm{FiO}_{2}: 0.3(0.01), \mathrm{SpO}_{2}: 95$ (1)\%, and $\mathrm{PCO}_{2}: 56$ (2) torr. The pressure-time products, per breath, and per minute, were respectively 14.6 (2) $\mathrm{cmH}_{2} \mathrm{O} / \mathrm{s}$ and $949(104) \mathrm{cmH}_{2} \mathrm{O} / \mathrm{s} / \mathrm{min}$ (Table 1).

Ten infants were randomly assigned to the nCPAP group and nine to the control group. The two groups were comparable for anthropometric parameters, severity scores, criteria of respiratory distress severity, and hemodynamic values. Four infants had been born prematurely, one in the nCPAP group and three in the control group, with a mean gestational age of $33(0.5)$ 
TABLE 1-Baseline Characteristics of the Population Randomized Into the Nasal Continuous Positive Airway Pressure (n-CPAP) and Control Groups

\begin{tabular}{lccc}
\hline & $\begin{array}{c}\text { nCPAP, } \\
\mathrm{n}=10\end{array}$ & $\begin{array}{c}\text { Controls, } \\
\mathrm{n}=9\end{array}$ & $P$-value \\
\hline Age (week) & $6.8(0.9)$ & $8.2(1.7)$ & 0.47 \\
Weight (kg) & $4.5(0.5)$ & $4.1(0.2)$ & 0.4 \\
$\mathrm{CRIB}$ & $1.9(0.2)$ & $2.4(0.5)$ & 0.93 \\
m-WCAS & $5(0.2)$ & $4.7(0.2)$ & 0.24 \\
$\mathrm{RR}$ (breaths/min) & $51(4.5)$ & $49(3.5)$ & 0.94 \\
$\mathrm{SpO}_{2}(\%)$ & $97(1)$ & $95(1.6)$ & 0.42 \\
$\mathrm{FiO}_{2}(\%)$ & $33(2)$ & $32(1.6)$ & 0.59 \\
$\mathrm{HR}^{(\text {beats/min) }}$ & $165(3)$ & $162(4)$ & 0.56 \\
$\mathrm{MAP}(\mathrm{mmHg})$ & $66(6)$ & $68(8)$ & 0.83 \\
$\mathrm{PCO}_{2}$ (torr) & $55(2)$ & $57(4)$ & 0.58 \\
$\mathrm{PTPes}_{\text {insp }} /$ breath $\left(\mathrm{cmH}_{2} \mathrm{O} / \mathrm{s}\right)$ & $14.6(0.9)$ & $14.6(1)$ & 0.99 \\
$\mathrm{PTPes}_{\text {insp }} / \mathrm{min}\left(\mathrm{cmH}_{2} \mathrm{O} / \mathrm{s} / \mathrm{min}\right)$ & $975(169)$ & $918(172)$ & 0.81 \\
\hline
\end{tabular}

CRIB, clinical risk index for babies; m-WCAS, modified Wood's clinical asthma score; $\mathrm{RR}$, respiratory rate; $\mathrm{SpO}_{2}$, pulse oximetry; $\mathrm{FiO}_{2}$, fraction of inspired oxygen; HR, heart rate; MAP, mean arterial blood pressure; $\mathrm{PCO}_{2}$, partial pressure of carbon dioxide measured on capillary blood gas sampling; PTPes ${ }_{\text {insp }}$, inspiratory muscle pressure-time product.

Values are expressed as mean (SEM).
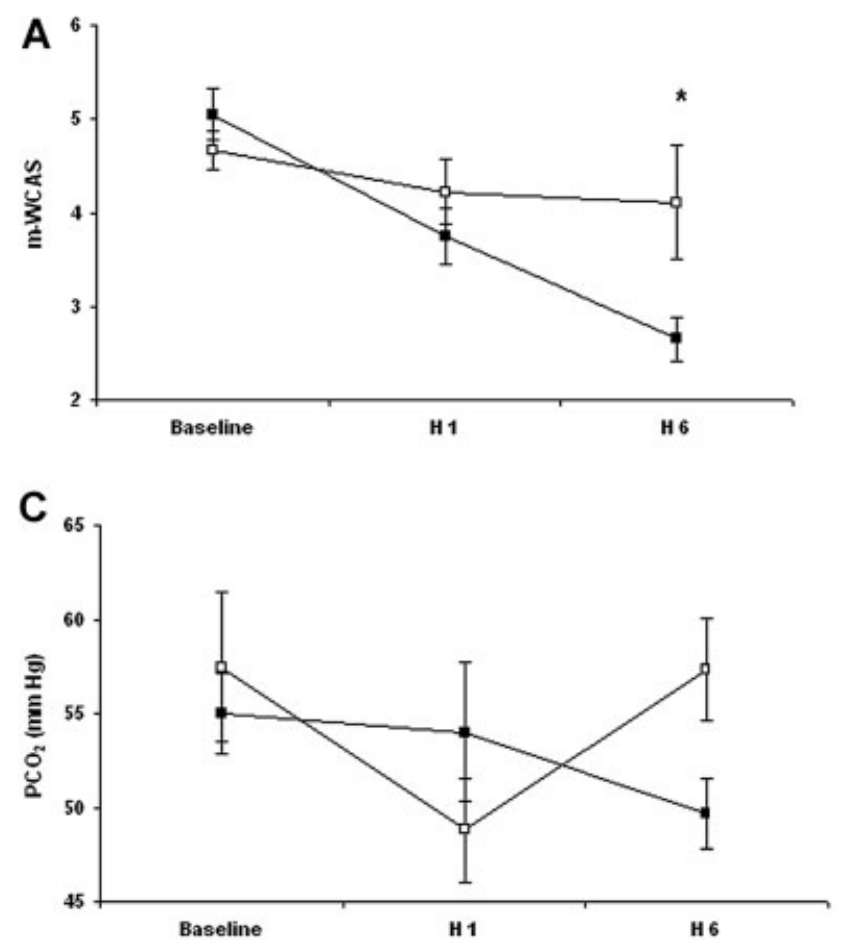

weeks and a mean birth weight of 2,170 (120) g; none had chronic lung disease.

Four infants in each group had received a nebulized $\beta$-adrenergic agent 4-6 hr before study enrollment. Corticosteroid treatment had been administered to three infants of the nCPAP group and two infants of the control group. These treatments had been stopped on admission to the PICU. The times between admission and enrollment in the nCPAP group and the control group were, respectively, 100 (33) and 200 (110) min; $P=0.7$.

\section{Comparison of the nCPAP and Control Groups}

\section{Clinical Improvement}

The m-WCAS decreased in the nCPAP group, whereas it remained unchanged in the control group. The linear model confirmed the variation in m-WCAS between $\mathrm{H} 0$ and $\mathrm{H} 6$ only in the nCPAP group [-2.4 (1.05) vs. -0.5 (1.3), $P=0.03$, Fig. 1A]. The decline in $\mathrm{m}$ WCAS between $\mathrm{H} 0$ and $\mathrm{H} 6$ in the nCPAP group was correlated with the m-WCAS value at H0, with a Spearman correlation coefficient of $0.64(P=0.04)$. In the control arm, we observed an inverse correlation between the m-WCAS value at $\mathrm{HO}$ and the difference
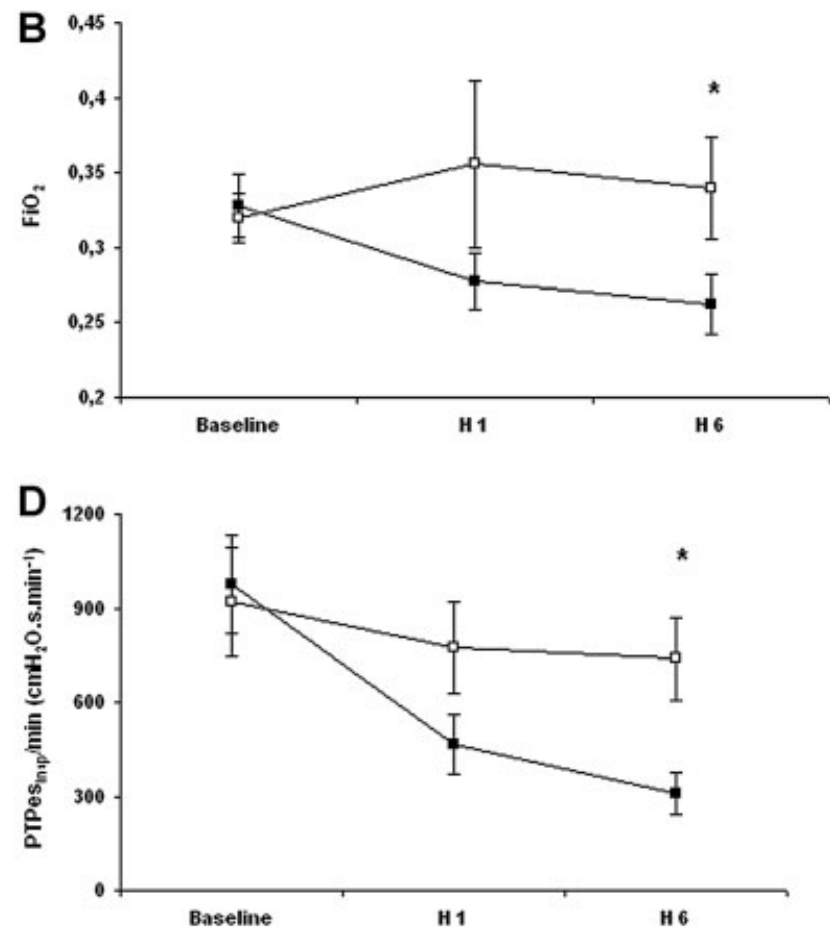

Fig. 1. Respiratory distress parameters at baseline $(\mathrm{HO}), 1(\mathrm{H} 1)$, and $6(\mathrm{H} 6) \mathrm{hr}$ in the nasal continuous positive airway pressure (nCPAP, black squares) and control (white squares) groups. A: Change in respiratory distress as assessed by the modified Wood's clinical asthma score (m-WCAS). B,C: Change in the fraction of inspired oxygen $\left(\mathrm{FiO}_{2}\right)$ and transcutaneous $\mathrm{PCO}_{2}$. D: Change in an index of respiratory work, the inspiratory muscle pressure-time product per minute (PTPes insp $/ \mathrm{min}$ ). Values are expressed as mean (SEM). ${ }^{*} \boldsymbol{P}<0.05$ using a linear mixed model for longitudinal data. 
between m-WCAS at $\mathrm{H} 0$ and H6, with a Spearman correlation coefficient of $-0.76(P=0.02$; Fig. 2; Table 2).

At H6, the respiratory rate in the nCPAP and control groups did not differ from the baseline values. The $\mathrm{FiO}_{2}$ required to maintain $\mathrm{SpO}_{2}$ within the target range remained stable from $\mathrm{H} 0$ to $\mathrm{H} 6$ in the two groups. However, the linear model revealed a significant difference in $\mathrm{FiO}_{2}$ variation during the study period between the groups $[-7$ (10) in the nCPAP group vs. +5 (15) in the control group, $P=0.049$, Fig. 1B].

Heart rate and mean arterial pressure showed no variation in either group.

\section{Gas Exchanges}

$\mathrm{PCO}_{2}$ decreased in the nCPAP group, from 55 (2) torr at $\mathrm{HO}$ to 49 torr (2) at H6; $P=0.047$. In the control group, $\mathrm{PCO}_{2}$ remained comparable (Fig. 1C). However, no inter-group difference was revealed in the linear model.

\section{Esophageal Pressure Measurements}

Placement of the neonatal esophageal balloon catheter was not possible in one patient because it induced excessive agitation. In three other patients, the recordings could not be interpreted, probably because of unsatisfactory positioning. Thus, the recordings were analyzed in 15 patients, eight in the nCPAP group and seven controls.

At H6, we observed a decrease in PTPes/breath and PTPes/min in the nCPAP group as compared with baseline values. In the control group, the variables at $\mathrm{H} 0$ and H6 did not differ. The linear model confirmed the greater reductions in $\mathrm{PTPes}_{\text {insp }} /$ breath $[-9.7$ (5.7) vs.

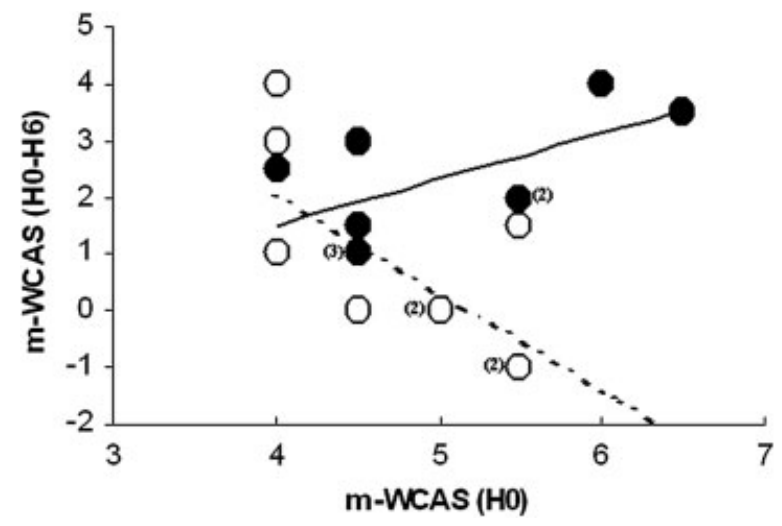

Fig. 2. Relationship between the baseline respiratory distress score using the modified Wood's clinical asthma score [mWCAS (H0)] and its change after $6 \mathrm{hr}$ [m-WCAS (HO-H6)] in the nasal continuous positive airway pressure (nCPAP, black circles) and control (white circles) groups. The correlation was significant in both groups, positive in nCPAP (solid line) and inverse in controls (dashed line).
TABLE 2-Change in Respiratory Distress in the Nasal Continuous Positive Airway Pressure (n-CPAP) and Control Groups, Assessed by the Difference in Clinical, Gas Exchange, and Esophageal Pressure Measurements Between Baseline (H0) and After 6 hr (H6)

\begin{tabular}{lcc}
\hline H0-H6 & nCPAP, & Controls, \\
$\mathrm{n}=10$ & $0.5(0.4)^{\mathrm{b}}$ \\
\hline m-WCAS & $2.4(0.4)^{\mathrm{a}}$ & $1.3(4)$ \\
$\mathrm{RR}($ breaths/min) & $7(4)$ & $2.4(3)$ \\
$\mathrm{SpO}_{2}(\%)$ & $0.7(1)$ & $-5(5)^{\mathrm{b}}$ \\
$\mathrm{FiO}_{2}(\%)$ & $7(3)$ & $2(4)$ \\
$\mathrm{HR}(\mathrm{beats} / \mathrm{min})$ & $9(7)$ & $-4(5)$ \\
$\mathrm{MAP}(\mathrm{mmHg})$ & $-4(6)$ & $4(4)$ \\
$\mathrm{PCO}_{2}($ torr $)$ & $6(2)^{\mathrm{a}}$ & $1.4(3)^{\mathrm{b}}$ \\
$\mathrm{PTPes}_{\text {insp }} / \mathrm{breath}\left(\mathrm{cmH}_{2} \mathrm{O} / \mathrm{s}\right)$ & $10(2)^{\mathrm{a}}$ & $116(117)^{\mathrm{b}}$ \\
$\mathrm{PTPes}_{\text {insp }} / \mathrm{min}\left(\mathrm{cmH}_{2} \mathrm{O} / \mathrm{s} / \mathrm{min}\right)$ & $666(134)^{\mathrm{a}}$ & \\
\hline
\end{tabular}

m-WCAS, modified Wood's clinical asthma score; RR, respiratory rate; $\mathrm{SpO}_{2}$, pulse oximetry; $\mathrm{FiO}_{2}$, fraction of inspired oxygen; $\mathrm{HR}$, heart rate; MAP, mean arterial blood pressure; $\mathrm{PCO}_{2}$, partial pressure of carbon dioxide measured on capillary blood gas sampling; PTPe$\mathrm{S}_{\text {insp }}$, inspiratory muscle pressure-time product.

Values are expressed as mean (SEM).

${ }^{\text {a }} P<0.05$ versus $\mathrm{H} 0$.

${ }^{\mathrm{b}} P<0.05$ versus nCPAP.

$-1.4(8.2) ; P=0.04)]$ and PTPes ${ }_{\text {insp }} / \mathrm{min}[-666$ (402) vs. -116 (352); $P=0.015]$ in the nCPAP group between H0 and H6 (Fig. 1D).

\section{Switching a Patient From One Group to the Other}

A switch to the other treatment group for a worsening clinical score $>30 \%$ concerned only the patients initially included in the control group: $4 / 9$ versus $0 / 10$ $(P=0.032)$. The change in group of the four patients occurred 1, 3, 4, and $5 \mathrm{hr}$ after the protocol had begun. After nCPAP was started in these infants, m-WCAS improved from 5.8 (1) to 2.5 (1.5); $P=0.039$. An illustration of the favorable effect of nCPAP on Pes swings is given in Figure 3. The severity of respiratory distress at admission and the anthropometric characteristics of this patient subgroup were not different from those of the rest of the cohort.

\section{Patient Outcomes}

None of the infants had to be intubated and none presented pneumothorax. In the nCPAP group, nCPAP lasted 72 (11) hr and hospital stay was $5(0.5)$ days. In the control group, nCPAP lasted 112 (12) hr for the four patients that changed groups during the study. The hospital stay for the control group was 5 (0.5) days.

\section{DISCUSSION}

This randomized, controlled study demonstrated that nasal CPAP reduced the clinical respiratory distress 


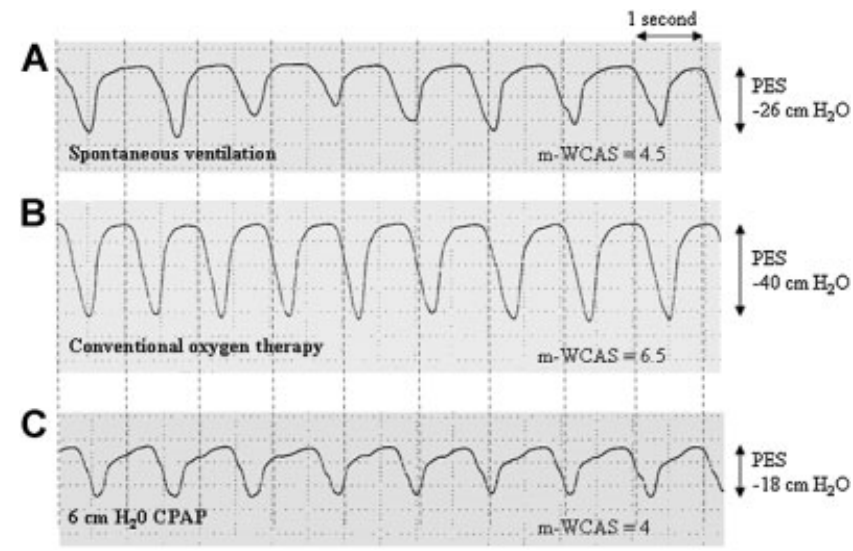

Fig. 3. Esophageal pressure (Pes) swings and concomitant respiratory distress score (m-WCAS) in an infant switched from oxygen therapy to nasal continuous positive airway pressure (nCPAP). At baseline, m-WCAS was 4.5 and Pes swings reached $26 \mathrm{cmH}_{2} \mathrm{O}$ during inspiration (A). The infant was randomized into the control group and received conventional oxygen therapy. After $1 \mathrm{hr}, \mathrm{m}$-WCAS increased to 6.5 and a new recording of Pes swings showed a dramatic increase to nearly $40 \mathrm{cmH}_{2} \mathrm{O}$ (B). Delivery of $+6 \mathrm{cmH}_{2} \mathrm{O} \mathrm{nCPAP}$ for $1 \mathrm{hr}$ induced decreases in both Pes swings $\left(18 \mathrm{cmH}_{2} \mathrm{O}\right)$ and the respiratory distress score (C).

score, the need for oxygen, and the respiratory muscle load in $<6$-month-old infants presenting acute severe RSV bronchiolitis. We observed that the higher the initial m-WCAS was, the greater the decrease in score when the infant was treated by nCPAP. Conversely, in infants who did not benefit from this ventilatory support, the higher the initial m-WCAS score was, the greater the tendency toward aggravation.

\section{What this Study Adds}

The current literature offers little justification for CPAP use except in cases of acute viral bronchiolitis with apnea. ${ }^{7,24}$ However, in the first randomized, control trial, Thia et al. ${ }^{10}$ confirmed the reduction in $\mathrm{CO}_{2}$ under CPAP. Although in our study we observed a similar drop in $\mathrm{CO}_{2}$ after $6 \mathrm{hr}$ of nCPAP, the dispersion in the values did not allow us to confirm a significantly different change compared with the group treated by oxygen therapy. Our study is original because it demonstrates an improvement in the clinical signs of respiratory distress that can objectively be attributed to the reduced inspiratory work under nCPAP.

\section{Practical CPAP Use in Acute Viral Bronchiolitis}

The standard pressure for first-intention CPAP in infants is between 4.5 and $6 \mathrm{cmH}_{2} \mathrm{O} .^{5,8,9,11}$ We used a predetermined pressure of $6 \mathrm{cmH}_{2} \mathrm{O}$ because it appeared both effective and safe in our pilot study. ${ }^{17}$ The effect of three increasing levels of nCPAP on breathing pattern, gas exchange, PEEPi and respiratory muscle work was recently reported. ${ }^{13}$ In this study, the use of an nCPAP level of $7 \mathrm{cmH}_{2} \mathrm{O}$ was associated with the greatest reduction in respiratory work, as assessed by esophageal and diaphragmatic pressuretime product per minute. However, the increase in CPAP pressure from 7 to $10 \mathrm{cmH}_{2} \mathrm{O}$ produced a further rise in respiratory muscle activity to overcome the high pressure applied. Precise adjustment of the pressure level to the individual PEEPi is not easy to achieve at the bedside of infants with acute bronchiolitis, because it requires combining esophageal and gastric pressure measurement with airflow monitoring. ${ }^{25}$

\section{Study Limitations}

Esophageal pressures were assessed using an orally inserted catheter with an external diameter of $1.9 \mathrm{~mm}$. In these conditions, the effect of this probe on inspiratory muscle work was probably modest, ${ }^{26}$ but this was not specifically evaluated. The difference in equipment used in the two groups precluded a blind study, and the small sample and short evaluation period were also limitations. Several authors, ourselves included, have reported that CPAP failure in the infant with acute respiratory distress occurs very early on, and always within the first $6 \mathrm{hr}$ of management. ${ }^{27-30}$ Our principal criterion, the change in m-WCAS, was not as powerful as the need for intubation, which generally serves as a reference in cases of acute respiratory distress. With our study design, we were unable to determine whether the infants switched to the nCPAP group would have eventually been intubated if they had remained under oxygen therapy.

\section{Perspectives}

Although the "CPAP effect" seems favorable for managing severe bronchiolitis, the problem of choosing the optimal interface has not been resolved. Several interfaces have been suggested, like the nasal $\operatorname{mask}^{7,11}$ and the bi-nasal cannula used in this study. ${ }^{5,8,9,17,21}$ Other interfaces seem promising, especially the helmet, which seems to be an effective and well-tolerated solution for this age and weight category. ${ }^{30-32}$ Also, the high-flow nasal cannula (HFNC) is very easy to put into place and is relatively inexpensive. ${ }^{33,34}$

A meta-analysis recently underlined the benefits of a mixture of air and helium, heliox, for signs of respiratory distress. ${ }^{2}$ These works open new perspectives for research to determine whether the combined use of CPAP and heliox can be validated for treatment of severe acute bronchiolitis in the young infant. ${ }^{21}$ 


\section{CONCLUSION}

nCPAP rapidly decreased the inspiratory muscle work in young infants with acute bronchiolitis. Improvement in the respiratory distress score at $6 \mathrm{hr}$ was proportional to the initial clinical severity, suggesting the importance of rapid initiation of nCPAP in the more severe forms of the disease.

\section{REFERENCES}

1. Smyth RL, Openshaw PJ. Bronchiolitis. Lancet 2006;368:312322.

2. Liet JM, Ducruet T, Gupta V, Cambonie G. Heliox inhalation therapy for bronchiolitis in infants. Cochrane Database Syst Rev 2010;4:CD006915.

3. Ventre K, Haroon M, Davison C. Surfactant therapy for bronchiolitis in critically ill infants. Cochrane Database Syst Rev 2006;3:CD005150.

4. Ventre K, Randolph A. Ribavirin for respiratory syncytial virus infection of the lower respiratory tract in infants and young children. Cochrane Database Syst Rev 2004;4:CD000181.

5. Beasley JM, Jones SE. Continuous positive airway pressure in bronchiolitis. Br Med J (Clin Res Ed) 1981;283:15061508.

6. Soong WJ, Hwang B, Tang RB. Continuous positive airway pressure by nasal prongs in bronchiolitis. Pediatr Pulmonol 1993;16:163-166.

7. McNamara F, Sullivan CE. Nasal CPAP treatment in an infant with respiratory syncytial virus-associated apnea. Pediatr Pulmonol 1997;24:218-221.

8. Larrar S, Essouri S, Durand P, Chevret L, Haas V, Chabernaud JL, Leyronnas D, Devictor D. Effects of nasal continuous positive airway pressure ventilation in infants with severe acute bronchiolitis. Arch Pediatr 2006;13:1397-1403.

9. Campion A, Huvenne H, Leteurtre S, Noizet O, Binoche A, Diependaele JF, Cremer R, Fourier C, Sadik A, Leclerc F. Noninvasive ventilation in infants with severe infection presumably due to respiratory syncytial virus: Feasibility and failure criteria. Arch Pediatr 2006;13:1404-1409.

10. Thia LP, McKenzie SA, Blyth TP, Minasian CC, Kozlowska WJ, Carr SB. Randomised controlled trial of nasal continuous positive airways pressure (CPAP) in bronchiolitis. Arch Dis Child 2008;93:45-47.

11. Javouhey E, Barats A, Richard N, Stamm D, Floret D. Noninvasive ventilation as primary ventilatory support for infants with severe bronchiolitis. Intensive Care Med 2008;34:16081614.

12. Hammer J, Numa A, Newth CJ. Acute respiratory distress syndrome caused by respiratory syncytial virus. Pediatr Pulmonol 1997;23:176-183.

13. Essouri S, Durand P, Chevret L, Balu L, Devictor D, Fauroux $\mathrm{B}$, Tissières $\mathrm{P}$. Optimal level of nasal continuous positive airway pressure in severe viral bronchiolitis. Intensive Care Med 2011; 37:2002-2007.

14. Smith TC, Marini JJ. Impact of PEEP on lung mechanics and work of breathing in severe airflow obstruction. J Appl Physiol 1988;65:1488-1499.

15. Tobin MJ, Lodato RF. PEEP, auto-PEEP, and waterfalls. Chest 1989;96:449-451.

16. Stokes GM, Milner AD, Groggins RC. Work of breathing, intrathoracic pressure and clinical findings in a group of babies with bronchiolitis. Acta Paediatr Scand 1981;70:689-694.
17. Cambonie G, Milési C, Jaber S, Amsallem F, Barbotte E, Picaud JC, Matecki S. Nasal continuous positive airway pressure decreases respiratory muscles overload in young infants with severe acute viral bronchiolitis. Intensive Care Med 2008; 34:1865-1872.

18. Hammer J. Nasal CPAP in preterm infants-Does it work and how? Intensive Care Med 2001;27:1689-1691.

19. Donlan M, Fontela PS, Puligandla PS. Use of continuous positive airway pressure (CPAP) in acute viral bronchiolitis: A systematic review. Pediatr Pulmonol 2011;46:736-746.

20. Hollman G, Shen G, Zeng L, Yngsdal-Krenz R, Perloff W, Zimmerman J, Strauss R. Helium-oxygen improves Clinical Asthma Scores in children with acute bronchiolitis. Crit Care Med 1998;26:1731-1736.

21. Martinón-Torres F, Rodríguez-Núñez A, Martinón-Sánchez JM. Nasal continuous positive airway pressure with heliox versus air oxygen in infants with acute bronchiolitis: A crossover study. Pediatrics 2008;121:e1190-e11955.

22. Cambonie G, Milési C, Fournier-Favre S, Counil F, Jaber S, Picaud JC, Matecki S. Clinical effects of heliox administration for acute bronchiolitis in young infants. Chest 2006;129:676682.

23. Collett PW, Perry C, Engel LA. Pressure-time product, flow, and oxygen cost of resistive breathing in humans. J Appl Physiol 1985;58:1263-1272.

24. Al-balkhi A, Klonin H, Marinaki K, Southall DP, Thomas DA, Jones P, Samuels MP. Review of treatment of bronchiolitis related apnoea in two centres. Arch Dis Child 2005;90:288-291.

25. Brochard L. Intrinsic (or auto-) positive end-expiratory pressure during spontaneous or assisted ventilation. Intensive Care Med 2002;28:1552-1554.

26. Greenspan JS, Wolfson MR, Holt WJ, Shaffer TH. Neonatal gastric intubation: Differential respiratory effects between nasogastric and orogastric tubes. Pediatr Pulmonol 1990;8:254-258.

27. Bernet V, Hug MI, Frey B. Predictive factors for the success of noninvasive mask ventilation in infants and children with acute respiratory failure. Pediatr Crit Care Med 2005;6:660-664.

28. Essouri S, Chevret L, Durand P, Haas V, Fauroux B, Devictor D. Noninvasive positive pressure ventilation: Five years of experience in a pediatric intensive care unit. Pediatr Crit Care Med 2006; 7:329-334.

29. Yañez LJ, Yunge M, Emilfork M, Lapadula M, Alcántara A, Fernández C, Lozano J, Contreras M, Conto L, Arevalo C, et al. A prospective, randomized, controlled trial of noninvasive ventilation in pediatric acute respiratory failure. Pediatr Crit Care Med 2008;9:484-489.

30. Milési C, Ferragu F, Jaber S, Rideau A, Combes C, Matecki S, Bourlet J, Picaud JC, Cambonie G. Continuous positive airway pressure ventilation with helmet in infants under 1 year. Intensive Care Med 2010;36:1592-1596.

31. Mayordomo-Colunga J, Medina A, Rey C, Concha A, Los Arcos M, Menéndez S. Helmet-delivered continuous positive airway pressure with heliox in respiratory syncytial virus bronchiolitis. Acta Paediatr 2010;99:308-311.

32. Codazzi D, Nacoti M, Passoni M, Bonanomi E, Sperti LR, Fumagalli R. Continuous positive airway pressure with modified helmet for treatment of hypoxemic acute respiratory failure in infants and a preschool population: A feasibility study. Pediatr Crit Care Med 2006;7:455-460.

33. Finer NN, Mannino FL. High-flow nasal cannula: A kinder, gentler CPAP? J Pediatr 2009;154:160-162.

34. McKiernan C, Chua LC, Visintainer PF, Allen H. High flow nasal cannulae therapy in infants with bronchiolitis. J Pediatr 2010;156:634-638. 